\title{
METEOROLOGICAL MONOGRAPHS
}

\section{BOARD OF EDITORS}

\section{Editor}

E. Wendeul Hewson

University of Michigan

J. J. Grorge

Eastern Air Lines

A. H. GlenN

A. H. Glenn and Associates

Ross GunN

U. S. Weather Bureau

W. C. JAcobs

Air Weather Service

J. KAPLAN

University of California, Los Angeles

\section{Assistant Editors}

\author{
A. Nelson Dingle \\ David L. Jones \\ University of Michigan
}

Associate Editors

METEOROLOGICAL MONOGRAPHS, a serial publication of the American Meteorological Society, serves as a medium for original papers, survey articles, and other material in meteorology and closely related fields; it is intended for material which is better suited in length or nature for publication in monograph form than for publication in the Journal of Meteorology, in the Bulletin of the American Meteorological Society or in Weatherwise. A METEOROLOGICAL MONOGRAPH may consist of a single paper or of a group of papers concerned with a single general topic.

\section{INFORMATION FOR CONTRIBUTORS}

Manuscripts for the METEOROLOGICAL MONOGRAPHS should be sent directly to the Editor: E. Wendell Hewson, Department of Civil Engineering, University of Michigan, Ann Arbor, Michigan. Manuscripts may be submitted by persons of any nationality who are members or nonmembers of the Society, but only manuscripts in the English language can be accepted. Every manuscript submitted is reviewed and in no case does the editor advise the author as to acceptability until at least one review has been obtained. Authors will receive galley proof but not page proof.

Manuscripts. The manuscript must be complete and in final form when submitted. It must be original typewritten copy on one side only of white paper sheets $81 / 2 \times 11$ inches, consecutively numbered; double spacing and wide margins are essential. Carbon copy and single spacing are not acceptable.

Each manuscript may include the following components, which should be presented in the order listed. Of these, the table of contents; title, author's name and affiliation; abstract; text; references; and legends are obligatory.

1. Title page. This will be prepared by the editor if the manuscript is accepted for publication.

2. Preface or foreword. A preface may be contributed by the sponsors of the investigation, or by some other interested group or individual. The preface should indicate the origin of the study and should present other facts of general interest which emphasize its importance and significance.
3. Table of contents. Chapter, section, and subsection headings should all be listed in the table of contents.

4. Title, author's name and affiliation. The affiliation should be stated as concisely as possible and should not constitute a complete address. The date of receipt of the manuscript is supplied by the editor.

5. Abstract. This should summarize the principal hypotheses, methods, and conclusions of the investigation. It should not include mathematical symbols or references to equation numbers, since the abstract is sometimes quoted verbatim in abstracting or reviewing journals.

6. Text. For one of a group of papers which together constitute a MONOGRAPH, it is sufficient to divide the text into sections, each with a separate heading, numbered consecutively. The section heading should be placed on a separate line, flush with the margin, and should not be underlined. Subsection headings, if needed, should be located at the beginning of certain paragraphs and underlined.

7. References. References should be arranged alphabetically and designated by numbers. The numbers are enclosed by brackets in the text but not in the alphabetical listing. When two or more references are involved, separate the numbers by semicolons: thus, "previous investigations $[3 ; 12 ; 27]$ have shown . . ."

Each reference listed should be complete and in the following form. For an article: author(s), year, title of article, title of serial publication (underlined), volume 


\section{METEOROLOGICAL MONOGRAPHS}

Volume 3

July 1957

Numbers 12-20

\section{METEOROLOGICAL RESEARCH REVIEW S: \\ summaries of progress from 1951 to 1955}

by

H. E. Landsberg; J. C. Bellamy;

J. S. Marshall and W. E. Gordon; S. Petterssen; T. F. Malone;

E. O. Hulburt; H. J. aufm Kampe, H. K. Weickmann.

Edited by Alfred K. Blackadar

Sponsored by the Geophysics Research Directorate

of the Air Force Cambridge Research Center,

Air Research and Development Command

PUBLISHED BY THE AMERICAN METEOROLOGICAL SOCIETY 3 JOY ST., BOSTON 8, MASS. 
ISBN 978-1-940033-19-8 (eBook)

DOI 10.1007/978-1-940033-19-8 


\section{METEOROLOGICAL MONOGRAPHS}

VOLUME 3

NUMBERS 12-20

1957

\section{CONTENTS}

No. 12. Review of Climatology, 1951-1955

by H. E. Landsberg

Pages

$1-43$

No. 13. Meteorological Instruments

by John C. Bellamy

$44-72$

No. 14. Radiometeorology

by J. S. Marshall and W. E. Gordon

73-113

No. 15. Weather Observations, Analysis, and Forecasting by Sverre Petterssen

$114-151$

No. 16. Applied Meteorology

by Thomas F. Malone

$152-159$

No. 17. Physics of the Upper Atmosphere

by E. O. Hulburt

$160-181$

No. 18. Physics of Clouds

by H. J. aufm Kampe and H. K. Weickmann

$182-225$

No. 19. Physics of Precipitation

by H. K. Weickmann

$226-255$

No. 20. Atmospheric Electricity

by H. J. aufm Kampe

$256-278$

Editor. Alfred K. Blackadar

Published and sold by

AMERICAN METEOROLOGICAL SOCIETY

3 JOY STREET, BOSTON 8, MASS. 


\title{
METEOROLOGICAL MONOGRAPHS
}

\author{
BOARD OF EDITORS
}

\section{Editor}

E. Wendell Hewson

University of Michigan
Assistant Editors

\author{
A. Nelson Dingle \\ David L. Jones \\ University of Michigan
}

\section{Associate Editors}

\section{J. J. George}

Eastern Air Lines

A. H. GlenN

A. H. Glenn and Associates

Ross GunN

U. S. Weather Bureau

W. C. Jacobs

Air Weather Service

J. KAPLAN

University of California, Los Angeles
H. E. LANDSBERG

U. S. Weather Bureau

R. B. Montgomery

Johns Hopkins University

H. A. Panofsky

Pennsylvania State University

G. M. Penner

Meteorological Service of Canada

H. RIEHL

University of Chicago

METEOROLOGICAL MONOGRAPHS, a serial publication of the American Meteorological Society, serves as a medium for original papers, survey articles, and other material in meteorology and closely related fields; it is intended for material which is better suited in length or nature for publication in monograph form than for publication in the Journal of Meteorology, in the Bulletin of the American Meteorological Society or in Weatherwise. A METEOROLOGICAL MONOGRAPH may consist of a single paper or of a group of papers concerned with a single general topic. 


\section{PREFACE}

The American Meteorological Society appointed the Committee for Collation and Organization of the Research Recommendations of Authors of the Compendium, known as CORRAC, early in 1954. Members of the committee were Daniel F. Rex, Cmdr., USN, Chairman, Dr. John C. Freeman, W. Ferguson Hall, Harry Press, and Dr. Jerome Spar. This committee agreed that its objectives could be most effectively carried out by presenting a series of survey articles, each of which would summarize in its field the recommendations contained in the Compendium of meteorology and review progress made since the preparation of these recommendations.

Fields originally selected by the committee for the survey articles were: physical meteorology, theoretical meteorology, weather observations, analysis and forecasting, meteorological instrumentation, and applied meteorology. Specialists were invited by the committee to write the reviews, and Professor James E. Miller was selected as editor. The articles contained in this volume embody the results of these plans with some modifications required by circumstances.

For many months the full responsibility for carrying out the details of this project was sustained by Professor Miller. He was a source of stimulation to the authors, helped them in defining the bounds and content of each article, set a pattern for style, and conducted a preliminary editing of four of the articles. His capable direction was interrupted by illness in April 1956, at which time his resignation as editor was reluctantly accepted.

Acknowledgments are due to Drs. Julius London, Richard M. Schotland, and Charles L. Hosler who have read portions of the manuscript and offered many suggestions. Professor Werner A. Baum has frequently furnished valuable advice on editorial problems. A large amount of help in clerical work and preparation of the index has been given by Mrs. Wilhelmina Lewis, Mrs. Sadelle Wladaver, Mrs. Charlotte Rakszawski, and Mrs. Myrtle Karsten. The business and financial arrangements were handled by Mr. Kenneth C. Spengler, Executive Secretary of the Society.

This volume has been published by the American Meteorological Society through sponsorship from the Geophysics Research Directorate, Air Force Cambridge Research Center, Air Research and Development Command, a portion under Contract W28-099 ac-399, and under Contract AF19(604)-1427.

\section{A. K. Blackadar}

\section{State College, Pennsylvania}

June 1957 


\section{CONTENTS OF VOLUME 3}

\section{July 1957}

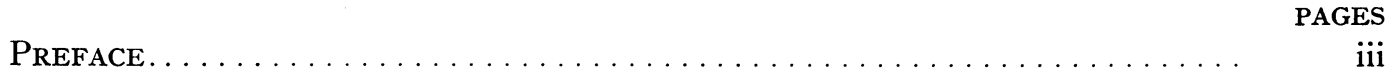

TABle of Contents................................... iv

No. 12. Review of Climatology, 1951-1955 .............. E. LANDSBERG 1-43

No. 13. Meteorological Instruments................. C. Bellamy 44-72

No. 14. Radiometeorology............ J. S. Marshall and W. E. Gordon 73-113

No. 15. Weather Observations, Analysis, and Forecasting.......S. Petrerssen 114-151

No. 16. Applied Meteorology....................... F. . MaLone 152-159

No. 17. Physics of the Upper Atmosphere............... O. Hulburt 160-181

No. 18. Physics of Clouds....... H. J. aufm Kampe and H. K. Weickmann 182-225

No. 19. Physics of Precipitation...................... Weickmann 226-255

No. 20. Atmospheric Electricity................. J. AUfm Kampe 256-278

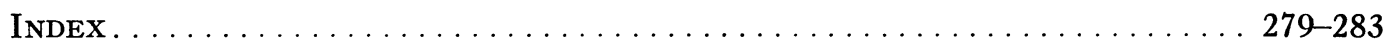

